\title{
Leaner-Centered College English Teaching
}

\author{
Lulu Zhou* \\ Changchun Normal University, Changchun, Jilin 130032, China.
}

\begin{abstract}
With the development of economic globalization, the world is increasingly inclined to exchange and cooperation. As the first language of international communication, English has become one of the basic abilities and qualities that modern people must have. In modern college English classroom teaching, the learner - centered college English teaching model has been widely used. Through the analysis of learners, teachers and teaching strategies, this paper tries to find out the relationship among them and the role they play in the learner-centered college English teaching, so as to improve the teaching strategies of college English and cultivate excellent English talents.
\end{abstract}

Keywords: Learner-Centered; Teaching Strategies; College English Teaching

\section{Introduction}

\subsection{Brief introduction of the research area}

With the rapid development of China's economy and the continuous extension of coastal areas to inland, more and more foreign companies choose to set their sights on the Chinese market. With the increase of foreign-funded enterprises, there is no doubt that language communication has received more attention as the most basic way of communication. In addition, because economic development is getting better, more and more people choose to travel abroad during the holidays. After experiencing the exotic style in a foreign country, come back and continue your struggle. Having a foreign language skill can help you travel abroad without the fear of a foreign country because you don't speak the language, and may give you an edge over others in the workplace. As English is the most widely used language in the world, education in our country starts from primary school to develop individual English learning ability. However, because the traditional teaching mode has not achieved as good results as expected, most people are still relatively weak in English communication.

\subsection{Significance of the study}

In traditional college English teaching, teachers simply impart knowledge. Teachers teach in the classroom. Students sit below and listen. In this mode of college English teaching, the center of teaching is teachers, not students. Under such a teaching mode, learners will have the idea that they are not the subject of learning, but the knowledge taught by the teacher is the most important idea. In such traditional English teaching, the learners are generally called dumb English by others. Dumb English is an English teaching method that places great emphasis on written English and test-oriented English. It seriously ignores oral expression and communicative English teaching methods. This method also cultivates the English ability of students who love it, and cannot understand or speak. But with the needs of social development, the comprehensive application of English is becoming more and more important.

\section{Learner in learner-centered college English teaching}

\subsection{Attitude of learners}

In the transformation of the teaching center from teacher to learner college English teaching, students have undoubtedly become the most important subject in this teaching process, so students' attitudes need to be changed. The student's change from what I want to learn to what I want to learn is not just to accept the knowledge taught by the teacher in the classroom without thinking, but to start thinking about why this is the case, and explore to discover more new knowledge ${ }^{[1]}$.

Learners need to be proactive in finding problematic attitudes. In the change of the teaching center, the learner as the subject of learning should actively discover the problems encountered in the learning process, not just staying on some questions that the teacher may ask, but thinking more about what else Aspects can be considered. Only when learners take the initiative to learn English and find some problems in their studies can they slowly experience the joy of learning English and fall in love with English learning.

\subsection{Ability of learners}

Copyright (C) 2020 Lulu Zhou

doi: 10.18282/l-e.v9i4.1736

This is an open-access article distributed under the terms of the Creative Commons Attribution Non-Commercial License (http://creativecommons.org/licenses/by-nc/4.0/), which permits unrestricted non-commercial use, distribution, and reproduction in any medium, provided the original work is properly cited. 
It is precisely because in the learner-centered college English teaching mode, learners become the center of teaching. Learners need to be more conscious to complete learning tasks.

Learners need to have planning skills, and they must do pre-class review, in-class focus, and after-school induction before English learning begins. Without the supervision of the instructor, these two steps are usually not taken seriously by the learner. Because it is not in class time, the two steps of pre-class review and after-class induction must occupy the learner's free time, so learners need to plan their free time to do pre-class review and post-class review.

Learners need mediation skills. When a question is raised, during the discussion between the learner and another learner, an unpleasant conversation may occur due to inconsistent ideas between the two parties. In this case, learners need to calmly mediate the unpleasant feelings of everyone and avoid unnecessary disputes.

\section{Teacher in learner-centered college English teaching}

\subsection{Attitude of teachers}

Teachers' first and most important job is, in order to improve learners' responsibility, to leave the priorities to learners but not the final decisions.

Teachers need to respond positively to changes in teaching models. Many teachers are relatively unfamiliar with the learnercentered college English teaching mode, because under the long-term traditional teaching mode, teachers have formed a relatively fixed teaching habit. These changes are tedious, so teachers need to actively respond to the changes brought about by this teaching mode.

Teachers need to be willing to accept changes in teaching methods brought about by changes in teaching models. Because there are many changes brought about by different teaching modes, many classrooms need to gradually apply new teaching methods. Therefore, teachers need to have a new college English teaching model, receive new teaching methods and change attitudes. Only by being willing to accept the changes brought about by the change of teaching mode can we get more progress in teaching work. Such changes benefit not only the learners but also the teachers ${ }^{[2]}$.

\subsection{Challenge and necessary changes of teachers}

With the continuous promotion of the new learner-centered college English teaching model, teachers are facing different teaching challenges from the traditional college English teaching model. In this era that can't resist the development of science and technology at all, the network is constantly improving, and now a network world has been formed. When the network becomes so convenient, teachers should make good use of the advanced things these technologies bring us.

Teachers are evaluators in the classroom. In traditional classrooms, teachers usually listen to recordings, learn words and read texts when teaching learners English. This kind of learning method is obviously not enough to meet the learner-centered college English teaching classroom, because the new college teaching classroom is mainly intended to strengthen learners' comprehensive ability to apply English, which can enable learners in daily life. Teachers need to give learners more opportunities to communicate in English. Because English is a foreign language that is completely different from our national language, some learners may have great difficulties in learning English.

\section{Teaching strategies in learner-centered college English teaching}

\subsection{Old teaching strategies}

Vocabulary is the basis for learning a foreign language. In traditional English teaching strategies, it is easy for teachers to focus on the form of their language. Such a tilt of focus allows learners to produce English as long as they learn the vocabulary, know those vocabularies, and understand the correct grammar. Under such cognition, learners will not pay attention to the study of English content, and learners will not pay too much attention to the study of English content.

In the context of exam-oriented education, performance seems to be the only criterion for assessing learners 'English learning, and teachers will pay more attention to learners' exam results. Under such circumstances, the learner will find it harder to get real English learning.

\subsection{New teaching strategies}

Learner-centered college English teaching no longer focuses on vocabulary and grammar, but focuses more on learners' English learning content. As long as learners become interested in English learning, many English knowledge learners will actively understand.

This new teaching strategy is not only a great help to the learning and thinking ability of the study group members, but also other learners in the classroom can be greatly improved, because the question explored may supplement their Time did not think of some aspects of knowledge. Teachers can see some aspects of learning knowledge that some teachers themselves have not taken into account, and they can more clearly know that learners may have questions about the classroom.

\section{Conclusion}

After analyzing learners, teachers, and teaching strategies, it is not difficult to find that learner-centered college English teaching requires the cooperation of these three to better develop college English teaching activities.

The relationship between learners and teachers is changing. In traditional college English teaching, learners carry out a lot of memory, imitation and a lot of drills. The teaching methods of teachers are mainly teaching and indoctrination. They do not give learners more space to think and discuss. As a result, learners have developed a dependence on teachers. Under this teaching mode, the learner and the teacher form an equal and respectful teacher-student relationship with each other. 


\title{
Construction of EH\&S Management System in Pharmaceutical Laboratories in University
}

\author{
Yijia Yuan* \\ School of Pharmaceutical Sciences, Sun Yat-sen University, Guangzhou 510006, China.
}

Abstract: Pharmaceutical science is an experimental subject involving many disciplines. As there are different kinds of risky factors, more and more attentions have been paid to the safety management of pharmaceutical laboratories. The article analyzes the deficiency of current safety management of pharmaceutical laboratories in domestic universities, draws on the EH\&S management model of universities in developed countries and explores measures to construct an EH\&S management system for pharmaceutical laboratories in domestic universities.

Keywords: EH\&S; Pharmaceutical Laboratories; Safety Management

\section{Introduction}

Safety management of pharmaceutical laboratories in colleges and universities involves the management of hazardous chemicals, biological safety, the use and maintenance of equipment with high temperature and high pressure and so on ${ }^{[1]}$. After the Reform and Opening-up, the construction of pharmaceutical laboratories began to develop and at the same time, domestic colleges and universities are paying increasing attention to the health and personal safety of the laboratories staff. However, due to insufficient management measures, there are still many potential safety hazards in domestic pharmaceutical laboratories, which is further worsened by the backward management system.

At present, the laboratories management in developed countries is generally in the charge of EH\&S (Environment, Health and Safety) management office, which is responsible for the safety of construction and management of the school laboratories. EH\&S management system aims at improving the environment and protecting the health and safety of laboratories personnel, which reflects the "people-oriented" management tenet of the colleges and universities in developed countries,.

As an incubator for high-end talents, pharmaceutical laboratories in colleges and universities are supposed to introduce the EH\&S safety management system. The construction of advanced laboratories is important for the development of education, which plays a vital role both practically and theoretically in our process of constructing world-class universities, high level colleges and an innovative country in the long term. Therefore, introducing EH\&S system to pharmaceutical laboratories in domestic universities and colleges is an international and inevitable trend for its safety management.

\section{Problems on safety management of pharmaceutical laboratories}

Pharmaceutical science is an experimental science involving intensive application, high technology and a comprehensive discipline-crossing with biology, chemistry, engineering, material and medicine. Therefore, the safety management of pharmaceutical laboratories in colleges and universities is more complicated. Although currently the responsibility system is applied for safety management, it is mostly carried out in a passive and dependent way, failing to guarantee daily implementation of safety regulations or investigate the potential risks.

\subsection{Loose structure of safety management}

Copyright (C) 2020 Yijia Yuan

doi: 10.18282/1-e.v9i4.1737

This is an open-access article distributed under the terms of the Creative Commons Attribution Non-Commercial License (http://creativecommons.org/licenses/by-nc/4.0/), which permits unrestricted non-commercial use, distribution, and reproduction in any medium, provided the original work is properly cited.

Teaching strategies need to be more in line with the times. When learner-centered college English teaching is widely used and the English level of the Chinese people is constantly improving, this also means that the education of English in our country is constantly developing, the degree of education is gradually increasing, and the talent team is growing. It is a great step forward on the road to the great rejuvenation of the Chinese nation.

\section{References:}

[1] Douglas Reimondo Robertson. Generative Paradox in Learner-Centered College Teaching[J]. Innovative Higher Education Volume 29, Issue 3, 2005.

[2] Abdurrahman KILIC. Learner-centered micro teaching in teacher education [J]. International Journal of Instruction Volume 3, Issue 1, 2010. 